\title{
K-CROSSING CRITICAL ALMOST PLANAR GRAPHS
}

\author{
Juwitha Rawung ${ }^{1)}$, Benny Pinontoan ${ }^{1)}$, Winsy Weku ${ }^{1)}$ \\ ${ }^{1)}$ Program Studi Matematika FMIPA Universitas Sam Ratulangi \\ Jl. KampusUnsrat, Manado 95115 \\ e-mail: juwitha_rifkerawung@yahoo.com;bpinonto@yahoo.com; winsyweku@gmail.com
}

\begin{abstract}
A graph is a pair of a non-empty set of vertices and a set of edges. Graphs can be drawn on the plane with or without crossing of its edges. Crossing number of a graph is the minimal number of crossing among all drawings of the graph on the plane. Graphs with crossing number zero are called planar. A graph is crossing critical if deleting any of its edge decreases its crossing number. A graph is called almost planar if deleting one edge makes the graph planar. This research shows graphs, given an integer $k \geq 1$, to build an infinite family of crossing critical almost planar graphs having crossing number $k$.
\end{abstract}

Keywords: Almost planar graph,crossing critical graph.

\section{GRAF $K$-PERPOTONGAN KRITIS HAMPIR PLANAR}

\begin{abstract}
ABSTRAK
Sebuah graf adalah pasangan himpunan tak kosong simpul dan himpunan sisi. Graf dapat digambar pada bidang dengan atau tanpa perpotongan. Angka perpotongan adalah jumlah perpotongan terkecil di antara semua gambar graf pada bidang. Graf dengan angka perpotongan nol disebut planar. Sebuah graf dinamakan perpotongan kritis jika penghapusan sebuah sisi manapun menurunkan angka perpotongannya, sedangkan sebuah graf dinamakan hampir planar jika menghapus salah satu sisinya membuat graf yang sisa menjadi planar. Dalam penelitian ini ditunjukkan graf, yang jika diberikan bilangan bulat $k \geq 1$, dapat menghasilkan famili takhingga graf perpotongan kritis hampir planar dengan angka perpotongan $k$.
\end{abstract}

Kata kunci: Graf hampir planar, graf perpotongan kritis.

\section{INTRODUCTION}

Graphs are among the most ubiquitous models of both natural and human-made structures. They can be used to model many types of relations and process dynamics in physical, biological and social systems. Many problems of practical interest can be represented by graphs.

A graph is an abstract representation of a set of objects where some pairs of the objects are connected by links. The interconnected objects are represented by mathematical abstractions called vertices, and the links that connect some pairs of vertices are called edges. Typically, a graph is depicted in diagrammatic form as a set of dots for the vertices, joined by lines or curves for the edges. The number of edge crossings of a graph is called number of crossing.The crossing numbercr $(G)$ of a graph $G$ is the lowest number of edge crossings of a drawing of the graph $G$. A graph with crossing number $\operatorname{cr}(G)=0$ is a planar graph, otherwise called a nonplanar graph.

Among many applications, the problem of crossing number very interesting and important because of its application in the optimization of chip area required in a circuit layout of Very Large Scale Integration or VLSI (Leighton, 1983 and Sherwani, 1998). Very Large Scale Integration (VLSI) is the process of creating integrated circuits by combining thousands of transistors into a single chip.The microprocessor is VLSI device. Minimizing the crossing here is also to reduce the risk of short circuit.

Structural properties of the crossing number problem studied through crossing critical graphs. A graph Gis $k$-crossing criticalif $\operatorname{cr}(G) \geq k$ and $\operatorname{cr}(G-e)<k$, for any 
edge $e$ of $G$. The first construction of an infinite family $K G_{n}$ of simple k-crossingcritical graphs was given by Kochol(1987).

A nonplanar graph $G$ is almost planar if deleting one edge (although not any edge) makes the graph planar (Mohar, 2006). The construction family of almost planar graph was given by Pinontoan (2011).

A question is conducting the topic in this research: "Are there $k$-crossing critical almost planar graphs?"

This research is limited for kpositive integer.

\section{LITERATURE REVIEW}

\section{VLSI}

Very Large Scale Integration (VLSI) is the process of creating integrated circuits by combining thousands of transistors into a single chip. VLSI began in the 1970s when complex semiconductor and communication technologies were being developed.

VLSI Physical Design Automation is essentially the research, development and productization of algorithms and data structures related to the physical design process. The objective is to investigate optimal arrangements of devices on a plane (or in three dimensions) and efficient interconnection schemes between these devices to obtain the desired functionality and performance. Since space on a wafer is very expensive real estate, algorithms must use the space very efficiently to lower costs and improve yield. In addition, the arrangement of devices plays a key role in determining the performance of a chip. Algorithms for physical design must also ensure that the layout generated abides by all the rules required by the fabrication process. Fabrication rules establish the tolerance limits of the fabrication process. Finally, algorithms must be efficient and should be able to handle very large designs. Efficient algorithms not only lead to fast turn-around time, but also permit designers to make iterative improvements to the layouts.

The VLSI physical design process manipulates very simple geometric objects, such as polygons and lines. As a result, physical design algorithms tend to be very intuitive in nature, and have significant overlap with graph algorithms and combinatorial optimization algorithms. In view of this observation, many consider physical design automation the study of graph theoretic and combinatorial algorithms for manipulation of geometricobjects in two and three dimensions (Sherwani, 1998).

\section{Application of Crossing}

Among many applications, the problem of crossing very interesting and important because of its application in the optimization of chip area required in a circuit layout of Very Large Scale Integration or VLSI (Leighton, 1983 and Sherwani, 1998). The microprocessor is VLSI device. Minimizing the crossing here is also to reduce the risk of short circuit.

\section{Graph}

A graph is a finite nonempty set of objects called vertices (the singular is vertex) together with a (possibility empty) set of unordered pair distinct vertices of $G$ called edges.

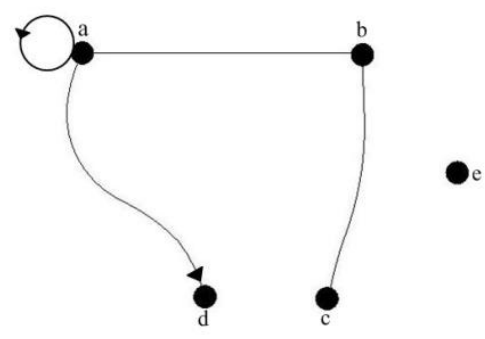

Figure 1 Example of Graph

Figure 1 provides an example of a graph on $V=\{a, b, c, d, e\} \quad$ with $E=$ $\{(a, a),(a, b),(a, d),(b, c)\}$.The direction of edge is indicated by placing a directed arrow on the edge, as shown here. For any edge, such as $(b, c)$ we say that the edge is incident with the vetices $b, c ; b$ is said to be adjacent to $c$, where as $c$ is adjacent from $b$. In addition, vertex $b$ is called the origin, or source, of the edge $(b, c)$ and vertex $c$ is the terminus or terminating vertex. The edge $(a, a)$ is an example of a loop and the vertex $e$ that has no incident edge called an isolated vertex.

A graph $G$ is called planar if $G$ can be drawn in the plane with its edges intersecting only at vertices of $G$ or a graph is planar if it can be drawn in a plane without graph edges crossing (i.e., it has graph crossing number 0) (Chartrand and Lesniak, 2000, Grimaldi, 1994). 


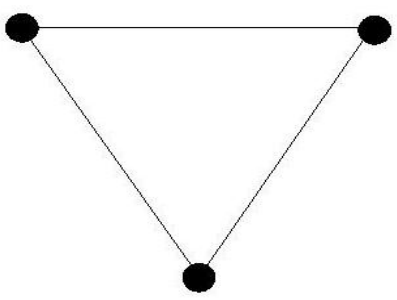

Figure 2 Planar Graph

\section{Crossing Number}

The concepts and terminology of crossing number used in this paper are taken from Cristov (2004), Ritcher and Pinontoan (2003).

The crossing number of a graph $G=(V, E)$ is $v(G)=\min \{\operatorname{cr}(D(G))\}$. Similarly, the crossing number $\operatorname{cr}(G)$ is the minimum number of crossings over all drawing of $G$.
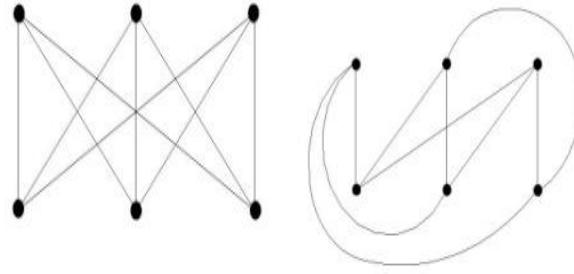

Figure $3 K_{3,3}$

In Figure 3 Graph $K_{3,3}$, drawing $K_{3,3}$ in the plane have one crossing so that $\operatorname{cr}\left(K_{3,3}\right)=1$.

\section{Crossing Critical Graph}

A graph $G$ is $k$-crossing critical if $\operatorname{cr}(G) \geq k$ and $\operatorname{cr}(G-e)<k$, for any edge $e$ of $G$. It is important to study crossing critical graphs in order to understand structural properties of the crossing number problem. The only 1-crossing critical graphs are subdivisions of $K_{5}$ and $K_{3,3}$. The first construction of an infinite family $K G_{n}$ of simple $k$-crossing critical graphs was given by $\operatorname{Kochol}(1987) . K G_{7}$ is shown in Figure 4 . He showed that thisgraph have crossing numbers two. This was an infinite family of 2-crossing critical of 3-connected simple graphs.

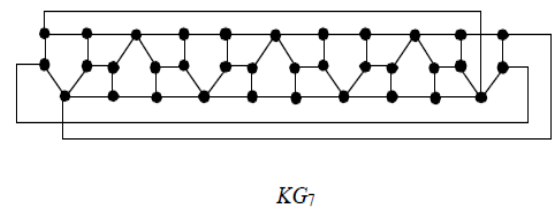

Figure 4

2-Crossing Critical of 3-Connected Simple Graphs

\section{Almost Planar Graph}

A graph $G$ is called almost planar if deleting one edge makes the graph planar. The construction family $G_{5,8}$ of almost planar graph was given by Pinontoan (2011). $G_{5,8}$ is shown in Figure 5.

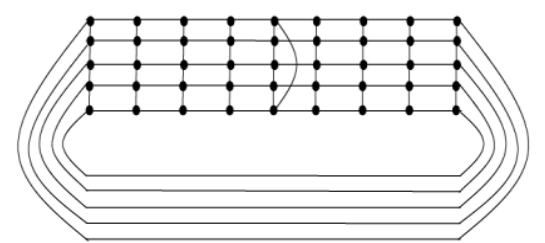

Figure 5 Family of Almost Planar Graph

Tile

The concepts and terminology of tile used in this paper are taken from Pinontoan and Richter (2003).

A tile is a 3-tuple $T=(G, L, R)$, where

- $G$ is a connected graph;

- $\quad L$ is a finite sequence of vertices of $V(G)$, called the left-wall;

- $R$ is a finite sequence of vertices of $V(G)$, called the right-wall; and all the vertices in $L$ and $R$ are

distinct.

Figure 6 shows some three examples of tiles: the tiles $K, M$, and $Z$. The left-wall of each of these tiles is the sequence $a b c$ and the rightwall is the sequence $d e f$ of vertices.
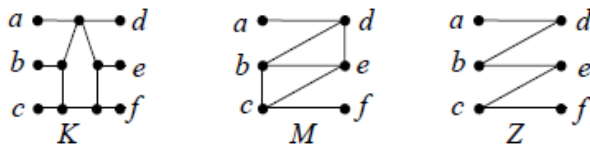

Figure 6 Tiles $\mathrm{K}, \mathrm{M}$ and $\mathrm{Z}$

\section{RESEARCH METHODS}

This research had use the literature study method from books and journals. From the literature study we can see, learn, showing existing result and develops it in 
constructing $k$-crossing critical almost planar graphs.

\section{RESULTS AND DISCUSSIONS}

Given an integer $k \geq 1$, there are infinite family of crossing critical almost planar graphs having crossing number $k$. With general form:

$G_{n}=\left\{V_{n}, E_{n} \mid n \geq 3\right\}$

$V_{n}=\left\{u_{1}, u_{2}, u_{3}, \ldots, u_{n}, v_{l}, v_{2}, v_{3}, \ldots, v_{n}\right\}$

$E_{n}=\left\{v_{k} u_{k} \mid 1 \leq k \leq n\right\} \cup$

$\left\{v_{k} v_{k+1} \mid 1 \leq k \leq n-1\right\}$

$\mathrm{U}$

$\left\{u_{k} u_{k+1} \mid 1 \leq k \leq n-1\right\} \cup \quad\left\{v_{1} u_{n}\right\}$ $\cup\left\{u_{k} v_{k+2} \mid 1 \leq k \leq n-2\right\}$

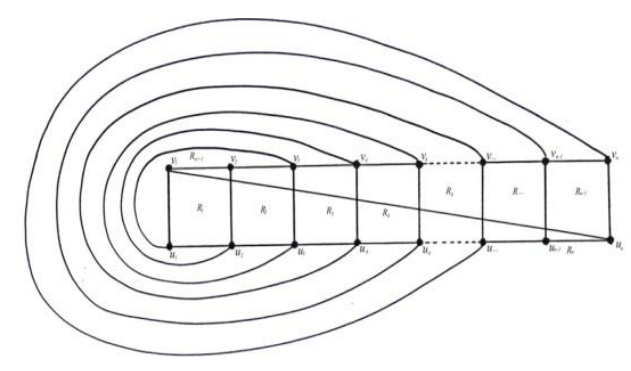

Figure $7 G_{n}$

$K$-Crossing Critical Almost Planar Graph

1.To show $G_{n}$ is crossing critical graph :

- $v_{1} u_{1}$ deleted $\rightarrow$ put $v_{1}$ in $R_{2}$ region $v_{1} u_{1}$ similar for $u_{n} v_{n}$

- $v_{1} v_{2}$ deleted $\rightarrow$ put $v_{1}$ in $R_{n}$ region $v_{1} v_{2}$ similar for $u_{n-1} u_{n}$

- $v_{k} v_{k+1}, 2 \leq k \leq n-1$ deleted $\rightarrow$ rerouted $v_{1} u_{n}$

- $u_{k} u_{k+1}, 1 \leq k \leq n-2$ deleted $\rightarrow$ rerouted $v_{1} u_{n}$

- $u_{k} v_{k+2,1} \leq k \leq n-2$ deleted $\rightarrow$ rerouted $v_{1} u_{n}$

- $v_{k} u_{k}, 2 \leq k \leq n-1$ deleted $\rightarrow$ clear

- $v_{1} u_{n}$ deleted $\rightarrow$ clear

2. To show $G_{n}$ is almost planar graph:

- $v_{1} u_{n}$ is deleted and it makes $G_{n}$ as a planar graph.

\section{Example 1-Crossing Critical Almost Planar Graphs}

$$
\begin{aligned}
& G_{3}=\left\{V_{3}, E_{3}\right\} \\
& V_{3}=\left\{u_{1}, u_{2}, u_{3}, v_{1}, v_{2}, v_{3}\right\} \\
& E_{3}=\left\{v_{k} u_{k} \mid 1 \leq k \leq 3\right\} \cup \\
&\left\{v_{k} v_{k+1} \mid 1 \leq k \leq 2\right\} \\
&\left\{u_{k} u_{k+1} \mid 1 \leq k \leq 2\right\} \cup \\
&\left\{u_{k} v_{k+2} \mid k=1\right\}
\end{aligned}
$$

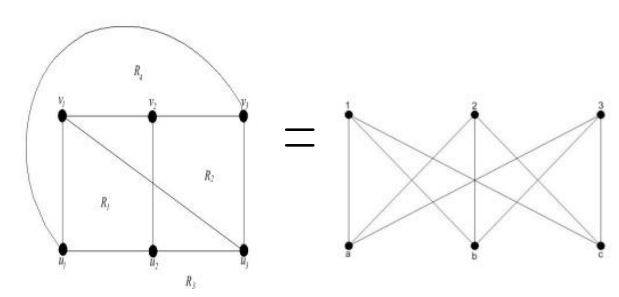

Figure 8 a) $G_{3}(\mathrm{~b}) K_{3,3}$

1-Crossing Critical Almost Planar Graph

Based on figure $8 G_{3}=K_{3,3}$ because $v_{1}=a$, $v_{2}=2, v_{3}=c, u_{1}=1, u_{2}=\mathrm{b}, u_{3}=3$.

We will show that $G_{3}$ is crossing critical almost planar graph.

1.To show $G_{3}$ is crossing critical graph :

- $v_{1} u_{1}$ deleted $\rightarrow$ put $v_{1}$ in $R_{2}$ region $v_{1} u_{1}$ similar for $u_{3} v_{3}$

- $v_{1} v_{2}$ deleted $\rightarrow$ put $v_{1}$ in $R_{3}$ region $v_{1} v_{2}$ similar for $u_{2} u_{3}$

- $v_{2} v_{3}$ deleted $\rightarrow$ rerouted $v_{1} u_{3}$

- $u_{1} u_{2}$ deleted $\rightarrow$ rerouted $v_{1} u_{3}$

- $u_{1} v_{3}$ deleted $\rightarrow$ rerouted $v_{1} u_{3}$

- $v_{2} u_{2}$ deleted $\rightarrow$ clear

- $v_{1} u_{3}$ deleted $\rightarrow$ clear

2. To show $G_{3}$ is almost planar graph:

- For 1-crossing critical almost planar graph, one of any edge of $G_{3}$ deleted makes $G_{3}$ as a planar graph.

\section{Example 2-Crossing Critical Almost Planar Graphs}

$$
\begin{aligned}
G_{4}= & \left\{V_{4}, E_{4}\right\} \\
V_{4}=\left\{u_{1}, u_{2}, u_{3}, u_{4}, v_{1}, v_{2}, v_{3}, v_{4}\right\} & \\
E_{4}=\left\{v_{k} u_{k} \mid 1 \leq k \leq 4\right\} \cup & \cup \\
& \left\{v_{k} v_{k+1} \mid 1 \leq k \leq 3\right\} \\
& \left\{u_{k} u_{k+1} \mid 1 \leq k \leq 3\right\} \cup \\
& \left\{u_{k} v_{k+2} \mid 1 \leq k \leq 2\right\}
\end{aligned}
$$

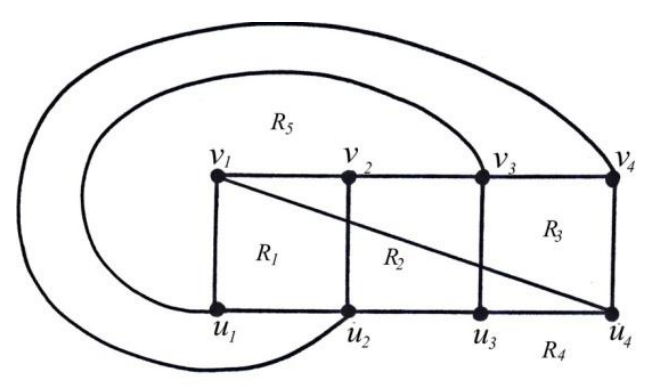

Figure $9 G_{4}$

2-Crossing Critical Almost Planar Graph 
We will show that $G_{4}$ is crossing critical almost planar graph.

1.To show $G_{4}$ is crossing critical graph :

- $v_{1} u_{1}$ deleted $\rightarrow$ put $v_{1}$ in $R_{2}$ region $v_{1} u_{1}$ similar for $u_{4} v_{4}$

- $v_{1} v_{2}$ deleted $\rightarrow$ put $v_{1}$ in $R_{4}$ region $v_{1} v_{2}$ similar for $u_{3} u_{4}$

- $v_{2} v_{3}$ or $v_{3} v_{4}$ deleted $\rightarrow$ rerouted $v_{1} u_{4}$

- $u_{1} u_{2}$ or $u_{2} u_{3}$ deleted $\rightarrow$ rerouted $v_{1} u_{4}$

- $u_{1} v_{3}$ or $u_{2} v_{4}$ deleted $\rightarrow$ rerouted $v_{1} u_{4}$

- $v_{2} u_{2}$ or $v_{3} u_{3}$ deleted $\rightarrow$ clear

- $v_{1} u_{4}$ deleted $\rightarrow$ clear

2. To show $G_{4}$ is almost planar graph:

- $v_{1} u_{4}$ is deleted and it makes $G_{4}$ as a planar graph.

\section{Example 3-Crossing Critical Almost Planar Graphs}

$G_{5}=\left\{V_{5}, E_{5}\right\}$

$V_{5}=\left\{u_{1}, u_{2}, u_{3}, u_{4}, u_{5}, v_{1}, v_{2}, v_{3}, v_{4}, v_{5}\right\}$

$E_{5}=\left\{v_{k} u_{k} \mid 1 \leq k \leq 5\right\} \cup$

$\left\{v_{k} v_{k+1} \mid 1 \leq k \leq 4\right\}$

$\left\{u_{k} u_{k+1} \mid 1 \leq k \leq 4\right\} \cup$

$\left\{u_{k} v_{k+2} \mid 1 \leq k \leq 3\right\}$

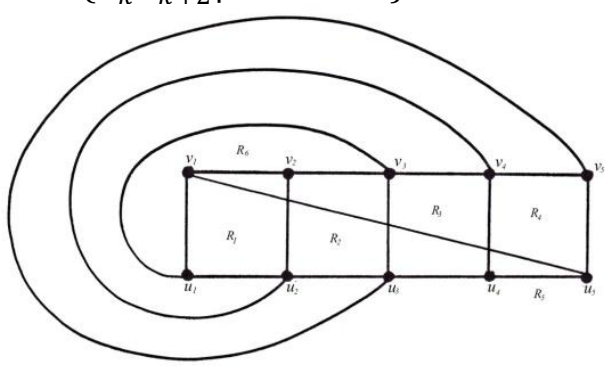

Figure $10 G_{5}$

3-Crossing Critical Almost Planar Graph

We will show that $G_{5}$ is crossing critical almost planar graph.

1.To show $G_{5}$ is crossing critical graph :

- $v_{1} u_{1}$ deleted $\rightarrow$ put $v_{1}$ in $R_{2}$ region $v_{1} u_{1}$ similar for $u_{5} v_{5}$

- $v_{1} v_{2}$ deleted $\rightarrow$ put $v_{1}$ in $R_{5}$ region $v_{1} v_{2}$ similar for $u_{4} u_{5}$

- $v_{2} v_{3}$ or $v_{3} v_{4}$ or $v_{4} v_{5}$ deleted $\rightarrow$ rerouted $v_{1} u_{5}$

- $u_{1} u_{2}$ or $u_{2} u_{3}$ or $u_{3} u_{4}$ deleted $\rightarrow$ rerouted $v_{1} u_{5}$

- $u_{1} v_{3}$ or $u_{2} v_{4}$ or $u_{3} v_{5}$ deleted $\rightarrow$ rerouted $v_{1} u_{5}$
- $v_{2} u_{2}$ or $v_{3} u_{3}$ or $v_{4} u_{4}$ deleted $\rightarrow$ clear

- $v_{1} u_{5}$ deleted $\rightarrow$ clear.

2. To show $G_{5}$ is almost planar graph:

- $v_{1} u_{5}$ is deleted and it makes $G_{5}$ as a planar graph.

\section{Example 4-Crossing Critical Almost Planar Graphs}

$G_{6}=\left\{V_{6}, E_{6}\right\}$

$V_{6}=\left\{u_{1}, u_{2}, u_{3}, u_{4}, u_{5}, u_{6}, v_{1}, v_{2}, v_{3}, v_{4}, v_{5}, v_{6}\right\}$

$E_{6}=\left\{v_{k} u_{k} \mid 1 \leq k \leq 6\right\}$

$\left\{v_{k} v_{k+1} \mid 1 \leq k \leq 5\right\}$

$\left\{u_{k} u_{k+1} \mid 1 \leq k \leq 5\right\} \quad \cup \quad\left\{v_{1} u_{6}\right\}$

$\left\{u_{k} v_{k+2} \mid 1 \leq k \leq 4\right\}$

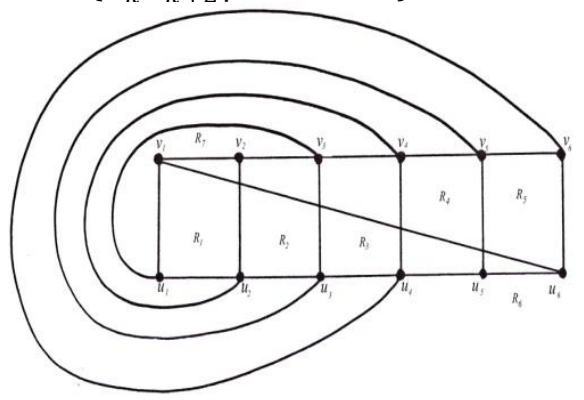

Figure $11 G_{6}$

4-Crossing Critical Almost Planar Graph

We will show that $G_{6}$ is crossing critical almost planar graph.

1.To show $G_{6}$ is crossing critical graph :

- $v_{1} u_{1}$ deleted $\rightarrow$ put $v_{1}$ in $R_{2}$ region $v_{1} u_{1}$ similar for $u_{6} v_{6}$

- $v_{1} v_{2}$ deleted $\rightarrow$ put $v_{1}$ in $R_{6}$ region $v_{1} v_{2}$ similar for $u_{5} u_{6}$

- $v_{2} v_{3}$ or $v_{3} v_{4}$ or $v_{4} v_{5}$ or $v_{5} v_{6}$ deleted $\rightarrow$ rerouted $v_{1} u_{6}$

- $u_{1} u_{2}$ or $u_{2} u_{3}$ or $u_{3} u_{4}$ or $u_{4} u_{5}$ deleted $\rightarrow$ rerouted $v_{1} u_{6}$

- $u_{1} v_{3}$ or $u_{2} v_{4}$ or $u_{3} v_{5}$ or $u_{4} v_{6}$ deleted $\rightarrow$ rerouted $v_{1} u_{6}$

- $v_{2} u_{2}$ or $v_{3} u_{3}$ or $v_{4} u_{4}$ or $v_{5} u_{5}$ deleted $\rightarrow$ clear

- $v_{1} u_{6}$ deleted $\rightarrow$ clear

2. To show $G_{6}$ is almost planar graph:

- $v_{1} u_{6}$ is deleted and it makes $G_{6}$ as a planar graph.

\section{Example 5-Crossing Critical Almost} Planar Graphs

$G_{7}=\left\{V_{7}, E_{7}\right\}$

$V_{7}=\left\{u_{1}, u_{2}, u_{3}, u_{4}, u_{5}, u_{6}, u_{7}, v_{1}, v_{2}, v_{3}, v_{4}\right.$, $\left.v_{5}, v_{6}, v_{7}\right\}$ 


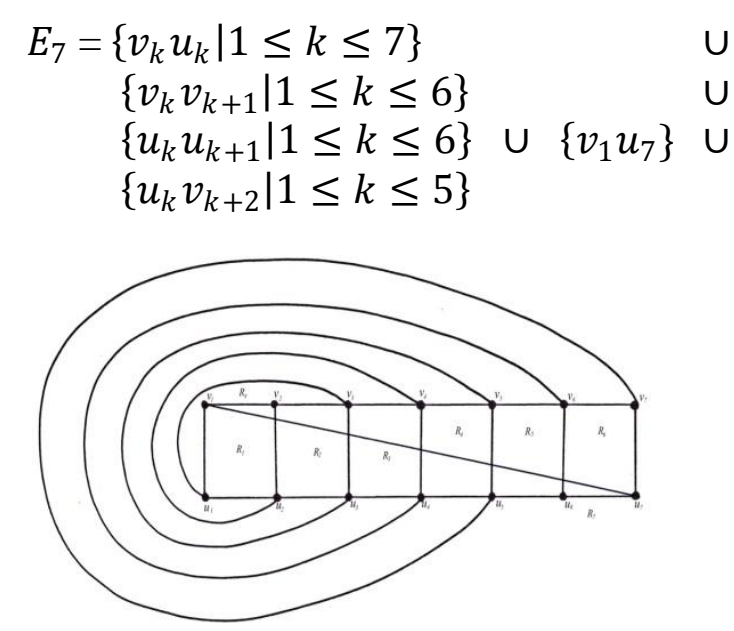

Figure $12 G_{7}$

5-Crossing Critical Almost Planar Graph

We will show that $G_{7}$ is crossing critical almost planar graph.

1.To show $G_{7}$ is crossing critical graph :

- $v_{1} u_{1}$ deleted $\rightarrow$ put $v_{1}$ in $R_{2}$ region $v_{1} u_{1}$ similar for $u_{7} v_{7}$

- $v_{1} v_{2}$ deleted $\rightarrow$ put $v_{1}$ in $R_{7}$ region $v_{1} v_{2}$ similar for $u_{6} u_{7}$

- $v_{2} v_{3}$ or $v_{3} v_{4}$ or $v_{4} v_{5}$ or $v_{5} v_{6}$ or $v_{6} v_{7}$ deleted $\rightarrow$ rerouted $v_{1} u_{7}$

- $u_{1} u_{2}$ or $u_{2} u_{3}$ or $u_{3} u_{4}$ or $u_{4} u_{5}$ or $u_{5} u_{6}$ de leted $\rightarrow$ rerouted $v_{1} u_{7}$

- $u_{1} v_{3}$ or $u_{2} v_{4}$ or $u_{3} v_{5}$ or $u_{4} v_{6}$ or $u_{5} u_{7}$ deleted $\rightarrow$ rerouted $v_{1} u_{7}$

- $v_{2} u_{2}$ or $v_{3} u_{3}$ or $v_{4} u_{4}$ or $v_{5} u_{5}$ or $v_{6} u_{6}$ deleted $\rightarrow$ clear

- $v_{1} u_{7}$ deleted $\rightarrow$ clear

2. To show $G_{7}$ is almost planar graph:

- $v_{1} u_{7}$ is deleted and it makes $G_{7}$ as a planar graph.

\section{CONCLUSION}

Given an integer $k \geq 1$, there exists an infinite family of crossing critical almost planar graphs having crossing number $k$.

\section{REFERENCES}

Chartrand, G. and L. Lesniak. 1996. Graphs and Digraphs $3^{\text {rd }}$ edition. Chapman and Hall, United State of Amerika.

Cristov, I. 2004. The Crossing Number of a Graph. Crossing Number, 1-6.
Grimaldi, R. P. 1994. Discreate and Combinatorial Introduction, $3{ }^{\text {rd }}$ Edition. Addison Wesley Publishing Company, Inc., USA.

Kochol, M., 1987. Construction of Crossing Critical Graphs. Disc. Math.66: 311313.

Leighton, F. T. 1983. Complexity Issues in VLSI.MIT Press, Cambridge, MA.

Mohar, B. 2006. On the Crossing Number of Almost Planars. Informatika 30: 301303.

Pinontoan, B. 2011. Construction of Infinite Families of Almost Planar Graph With Given Crossing Number. Jurnal Ilmiah Sains. 11(2): 150-157.

Pinontoan, B., and Richter, R.B. 2003.Crossing Numbers of Sequences of Graphs II: Planar Tiles. J. Graph Theory.42: 332-341.

Sherwani, N.A. 1998. Algorithm for VLSI Physical design automation, Kluwer Academic Publishers, Massachusetts, USA. 